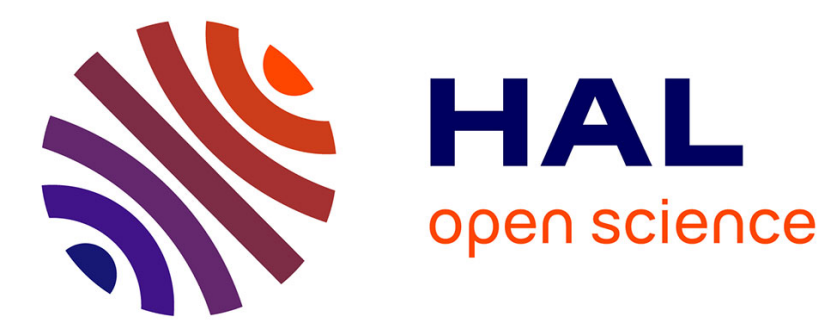

\title{
Coping Strategies of Families in HIV/AIDS Care: Some Exploratory Data from Two Developmental Contexts.
}

\author{
George Varghese Palattiyil, Mono Chakrabarti
}

\section{To cite this version:}

George Varghese Palattiyil, Mono Chakrabarti. Coping Strategies of Families in HIV/AIDS Care: Some Exploratory Data from Two Developmental Contexts.. AIDS Care, 2008, 20 (07), pp.881-885. 10.1080/09540120701767166 . hal-00513438

\section{HAL Id: hal-00513438 \\ https://hal.science/hal-00513438}

Submitted on 1 Sep 2010

HAL is a multi-disciplinary open access archive for the deposit and dissemination of scientific research documents, whether they are published or not. The documents may come from teaching and research institutions in France or abroad, or from public or private research centers.
L'archive ouverte pluridisciplinaire HAL, est destinée au dépôt et à la diffusion de documents scientifiques de niveau recherche, publiés ou non, émanant des établissements d'enseignement et de recherche français ou étrangers, des laboratoires publics ou privés. 

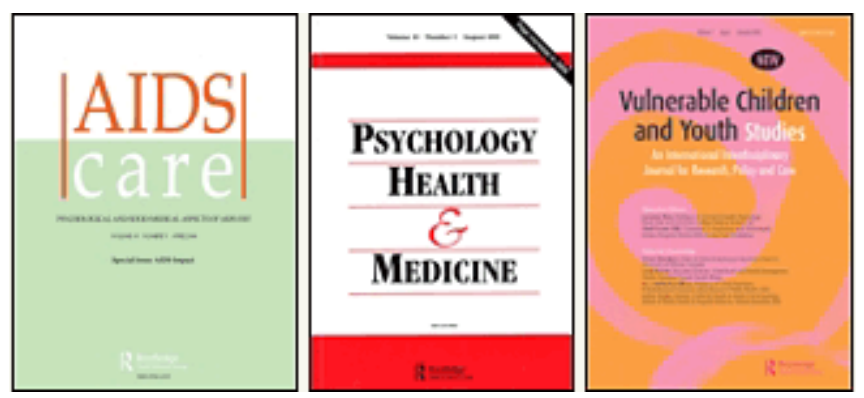

\section{Coping Strategies of Families in HIV/AIDS Care: Some Exploratory Data from Two Developmental Contexts.}

\begin{tabular}{|r|l|}
\hline Journal: & $\begin{array}{l}\text { AIDS Care - Psychology, Health \& Medicine - Vulnerable Children } \\
\text { and Youth Studies }\end{array}$ \\
\hline Manuscript ID: & AC-2007-02-0066.R1 \\
\hline Journal Selection: & AIDS Care \\
\hline Keywords: & $\begin{array}{l}\text { HIV/AIDS, Family caregiving, Coping strategies, Developmental } \\
\text { context, Stigma and discrimination }\end{array}$ \\
\hline \multicolumn{2}{|l}{} \\
\hline
\end{tabular}

\section{S ScholarONE" \\ Manuscript Central}




\section{Coping Strategies of Families in HIV/AIDS Care: Some Exploratory Data from Two Developmental Contexts.}

\section{Introduction}

The HIV/AIDS epidemic has fundamentally transformed the world (Annan, 2006) in the quarter century since the first cases were reported. Twenty-five years on, the global response to HIV/AIDS stands at crossroads (UNAIDS, 2006). On the one hand there is a global scaling up of efforts to contain the epidemic (Annan, 2006) and on the other, are the imperceptible struggles borne on a day-to-day basis by families who support their members living with HIV/AIDS,

Almost universally, families provide the bulk of care and support for persons living with HIV/AIDS (UNAIDS, 2004), despite the unique threat that HIV poses to family unity and wellbeing (Akintola, 2003; Hong, Nguyen, \&_Ogden, 2004). Caring for a family member with HIV/AIDS presents multiple challenges to the carer and to the family, including physical and emotional suffering, socio-economic vulnerability, and increased vulnerability to $\mathrm{HIV}_{\mathrm{z}}$ itself (Ogden, Simel, \& Caren, 2004). Since the beginning of the epidemic, stigma and discrimination have also been identified_as important sources of personal suffering (Piot, 2006), and as key challenges to effective caring in the family. A number of studies (Armstrong, 2000; Juma, Okeyo, \& Kidenda, 2004; Knodel, Zimmer, Kim, \& Puch, 2006) have shown how HIV/AIDS can destabilise and destroy families and communities that have previously provided strong networks of support to their members. Faced with challenges of limited resources, multiple burdens, and discrimination, the family carer must find a way to manage the stress of caregiving and hold the family together. The carer's coping efforts will influence his or her well-being and the well-being of the family as a whole.

Deleted: into the HIV/AIDS epidemic 
Sharp contrasts exist in the conditions faced by carers in developed countries versus those in the developing world. In developed nations, progress in medical care, the availability of antiretroviral treatment, and other statutory benefits have favourably influenced the circumstances faced by the carers. In resource-poor countries, limited access to medical facilities, poverty, and pervasive stigma and discrimination have made for a much harsher reality of HIV/AIDS caregiving.

A few studies (O’Neil \& McKinney, 2003; Ogden et al, 2004) have examined the ways that carers cope with the strains of caregiving; however, there is very little evidence on the impact of development on the carers' ability to cope with the strains of HIV/AIDS care. As a first step to addressing this issue, this exploratory study was carried out in two developmental contexts, Kerala (India) and Scotland (UK), to examine the ways in which family carers managed the challenges of caregiving.

\section{Method}

This paper focuses on the area of coping and is drawn from a larger study that looked at experiences, coping and mental health of family carers of persons living with HIV/AIDS across two contexts of development. Kerala is a small state in India that has the distinction of having achieved 100\% literacy (McKibben, 2005). It provides a unique model of development (Dreze \& Sen, 1999) because it has been able to achieve exceptional progress in health, education, and demographic transition despite low economic development. However, it cannot be said that progress has been evenly felt; there is noticeable disparity between the north and the south (the south being more developed), and the differences between the urban and rural areas are quite visible.

What is striking, however, is the attitude of people in Kerala to HIV/AIDS (Newton, 2001). One would imagine that a population with high literacy, social development and political
Deleted: an atmosphere of

Deleted: coped with

Deleted: ๆ

I

Deleted: is
Deleted: e
Deleted: current study was conducted
as part of a larger investigation of family
caregiving and HIV/AIDS in
Deleted: - Kerala, India and Scotland,
UK.


awareness would have a greater understanding of and tolerance towards people with HIV/AIDS. However the stigma that continues to trouble many HIV/AIDS patients in India (Bharat, Aggleton, \& Tyrer, 2001) is very much a problem in Kerala, often denying them access to health care and forcing HIV/AIDS-positive persons and their carers into isolation, and sometimes forcing them to flee for their safety. The social realities of the carers in Kerala were characterised by poverty, lack of medical resources/testing facilities, lack of access to combination therapy, absence of social security, and inadequate formal social support networks.

Scotland, on the other hand, is a developed European welfare state, with statutory measures to achieve basic living standards and help those in need. Scotland has an established National Health Service, national insurance, and family allowances. Scotland had a high prevalence of HIV/AIDS during the early days of the epidemic in the UK; however the advances in HIV treatment and management, together with newer laws have brought about considerable changes in the way HIV is perceived both by HIV-positive persons themselves and by society in general. The key social realities of the carers in Scotland are the presence of a comparatively high standard of living, the introduction of combination therapies, established social security measures, and availability of formal support networks, as well as formal recognition of the role of carers.

Using purposive sampling, 28 participants (23 in Kerala; 5 in Scotland) were recruited through agencies providing support to patients and carers. The sample size in Scotland was relatively small because of difficulties encountered in locating family carers who could participate. Ethical issues were woven through all aspects of the study and the researcher gave particular importance to issues of confidentiality, informed consent, trust, and $\underline{\text { reciprocity, given the sensitive and cross-cultural nature of the resaerch. }}$

A majority of the carers in Kerala were under the age of 40 , with the largest group $(43.5 \%)$ falling in the age range of 31 to 40 years and the second largest group (34.8\%) falling between the ages of 21 and 30 years. The Scottish group, though considerably smaller, was more spread across the age range from 31 to 60 years of age. The majority of the respondents in both settings were female, accounting for some $74 \%$ of the Kerala sample and $80 \%$ of the
Deleted: Purposive sampling was used to select 28 participants (23 in Kerala; 5 in Scotland). Most were recruited through agencies providing support to patients and carers. 
Scotland sample. Most of the carers in Kerala were the wives of the person living with HIV/AIDS, although a few parents and siblings served as carers. In the Scotland sample, the majority of the carers were parents of the individual with HIV.

A modified version of the Revised Ways of Coping (WOC) scale (Folkman, Lazarus, Dunkel-Scheller, DeLongis, \& Gruen, 1986) was used to measure coping strategies. To capture strategies that might be more appropriate for HIV/AIDS carers, a few items were added. The final scale was an 85 -item questionnaire containing a wide range of thoughts and acts that people use to deal with specific stressful encounters. The questionnaire used a YesNo response format in order to simplify the administration process for individuals who were not used to responding to the Likert scale format. Each item was given a score of 1 if the respondent indicated that he or she had used that coping strategy, and a score of 0 if the strategy was not used. The items were grouped into nine subscales reflecting the original groupings made by Folkman et al (1986).

For participants from Kerala, the WOC was translated and administered in an interview format. Participants in Scotland had the option of completing the WOC scale in an interview or returning the questionnaire by mail. The procedures for completing the WOC scale varied between the two contexts because of fundamental differences in the resources available. The carers in Kerala did not have privacy to complete a form, ability to spend time for themselves, or infrastructure such as post boxes in close vicinity, and thus completing and mailing a form was a considerable burden, hence the appropriateness of the interview method to their needs.

Scores were derived by summing positive responses to the scale items for each subscale and for the total across all items. Internal consistency coefficients (Cronbach's alpha) were
Deleted: 9

Deleted: The practice of adding items to the standard form of the WOC is in keeping with the recommendations of the authors of the scale, who encourage researchers to adapt the scale to specific study contexts.

Deleted: The researcher translated each item into the vernacular and noted the carer's response as it was given. 
computed for each of the nine scales of the revised WOC, as well as for the total score. Internal consistency was computed across the entire sample rather than for the separate groups because of the small size of the Scotland sample.

The internal consistency for the total scale was .74, suggesting fairly good internal consistency for the total sample. The internal consistencies of the nine subscales varied considerably, from an extremely low coefficient of .01 for the Distancing/Detachment scale to a modestly high coefficient of .68 for the Seeking Social Support scale. These scores likely reflect the small sample size and the brevity of some of the subscales, and may be disappointing from a pure psychometric perspective; however, they reflect prior experience with the WOC, (Schwarzer \& Schwarzer, 1996) and they are consistent with the theoretical understanding of the coping process. As Schwarzer and Schwarzer noted, internal consistency may not be expected or desirable when the goal is to measure real-life coping efforts. The complexity of stressful events and the efforts to cope with them may lead to individual and situational variability that works against consistent measurement.

The total scores on the WOC were compared for the Kerala and Scotland samples using the Mann-Whitney $\mathrm{U}$ test. This nonparametric test was chosen because of the small size of the Scotland sample, which made it impossible to satisfy the statistical requirements for a parametric test. Scores on selected subscales were also compared using this method. Comparisons were made only on scales having internal consistency coefficients greater than .50. 


\section{Findings and Discussion}

The respondents' WOC scores were summed across all of the 85 items of the revised scale in order to get a sense of the repertoire of coping strategies used by the respondents in each setting. Since the modified response format assigned a score of 1 for each item endorsed, the total score represents the total number of different coping strategies endorsed by each respondent. The median number of items endorsed by the Kerala respondents was 34 (range 26 to 44), while that for the Scotland respondents was 50 (range 37 to 55). The scores for the two groups were compared using the Mann-Whitney U Test, and the results were statistically significant $(U=8.00, p=.003)$. Thus it appears that the respondents from Scotland used a larger number of coping strategies than the respondents from Kerala. This difference was reflected in the way the carers narrated their experiences. Carers in both communities mentioned experiences of stigmatization and discrimination, but these experiences were much more severe for the respondents in Kerala. Family carers from Kerala were subject to discrimination, isolation, ostracism, and marginalisation, as well as verbal abuse. In an extreme case, there was one carer who carried a sachet of poison in case life became so unbearable that she needed to end her life.

To get an idea of how the two groups used different types of coping strategies, the median scores on selected WOC subscales with internal consistency greater than .50 were computed for the Kerala and Scotland samples.

Scores were compared using the Mann-Whitney U Test, and the results for the selected subscales are presented in Table 1 . It should be noted that the size of the Scotland sample
Deleted: WOC Total Scores

Deleted: WOCscale

Deleted: q

WOC Subscale Scores

Deleted: The results are presented in Table 1.

I

Table 19

Table 19

I

Median Scores for Coping Scales in Kerala $(n=23)$ and Scotland $(n=5)$ व I

Scale

Deleted: 2 
used in these analyses was very small $(n=5)$. Because of this, these results should be interpreted with some caution.

| Table 1

Deleted: 2

Mann-Whitney U Tests for Ways of Coping Subscales

\begin{tabular}{lcc}
\multicolumn{1}{c}{ Scale } & Mann-Whitney U & Significance (two-tailed) \\
\hline Problem Focused Coping & 20.00 & .022 \\
Positive Reappraisal & 6.00 & .002 \\
Seeking Social Support & 9.50 & .003 \\
Self Blame & 27.50 & .043
\end{tabular}

The Kerala and Scotland samples differed significantly on the four selected WOC measures. Respondents from Scotland earned significantly higher scores for Problem Focused Coping, Positive Reappraisal, and Seeking Social Support. Respondents from Kerala earned significantly higher scores for Self Blame. Although these data are exploratory, they do suggest differences in the ways that the respondents in the two setting used coping strategies. The respondents from Scotland appeared to use a greater variety of coping responses.

These differences may reflect the disparity in resources available to the family carers in the two settings. Thoits (1986) suggested the importance of social support for coping with stress in general, and Reidy (as cited in Catalan et al, 1997) and McGough (1990) noted the benefits of social support for HIV/AIDS carers. The burdens associated with providing care for a family member with HIV/AIDS created a great need for additional social support, yet ironically for most of the carers in Kerala this support was not forthcoming. The stigma and fear associated with HIV/AIDS seemed to create a barrier that either prevented the carers in Kerala from asking for support or kept them from receiving it. They faced a remarkable lack 
of formalised support services as well; formal services for the much needed psycho-social support were virtually non-existent. The carers in Scotland seemed to fare better in terms of informal support. A majority $(4, \mathrm{n}=5)$ mentioned strong support from family of origin; likewise there was a much higher level of counselling support together with a well-developed system for delivery of medical care and protection of patient rights. Nonetheless, a few carers reported that they found few resources directed towards them in their role as carers. It is possible that these improved conditions in Scotland allowed for the use of a wider variety of coping strategies.

Many coping strategies require that the carers have access to resources (Ogden et al, 2004). For example, a carer cannot use social support as a coping strategy unless there are people available to provide support. Similarly, the carers cannot look for advice unless such advice is available. For the Kerala respondents, the array of resources was much smaller, and thus many of the strategies were impossible for them. In particular, the atmosphere of secrecy and threat that surrounds HIV/AIDS patients in Kerala may have prevented them from seeking assistance from others, out of fear that the HIV status of the family member would be revealed. Many carers lived in fear that the HIV status of the cared-for would be discovered and would lead to their expulsion from their homes. A report by Human Rights Watch (HRW, 2004) poignantly illustrates this reality. They cite an incident in July 2004 where two HIV-positive children were thrown out of a school in Kerala until the Government intervened. However, even afterwards they were segregated from other students and taught by a specially appointed teacher. HWR reported that some of their respondents were willing to meet only outside of their neighbourhoods for fear that their visit would reveal their HIVpositive status to their neighbours. Not surprisingly, one respondent in this study said that if
Deleted: too

Deleted: ;

Deleted: there were very little

Deleted:

Deleted: of carers of persons with HIV/AIDS

Deleted: were virtually non-existent

Deleted: somewhat

Deleted:

Deleted: , a

Deleted: is

Deleted: was a

Deleted:

Deleted: ,

Deleted: though

Deleted: certain

Deleted: the necessary
Deleted: and had them readmitted into a government school.

Deleted: However, even 
the community discovered his status, he would commit suicide, because he feared that he would be stoned to death.

Patterson (1988) has pointed out the importance of balance between demands and resources for caregiving families. For the Kerala participants, there was a lack of such balance, which could signal a failure of coping efforts for many of the carers. The carers in Kerala have to cope not only with the burdens imposed by HIV/AIDS, but also with the burdens of poverty and lack of access to proven medical treatment. These fundamental issues are likely to influence the more personal coping experiences of the carers. The success of the family's coping efforts may depend on the resources available to the family. Direct efforts to reduce stress by improving the health of the HIV/AIDS-affected person require resources such as access to medicines and medical care, money, and a range of other material resources. Indirect coping efforts may also require resources, such as an appropriate social support network or counselling services, which were in limited supply in Kerala.

The process of coping with caregiving for HIV/AIDS is thus closely tied to the context in which it occurs. Issues such as stigma and marginalisation, lack of medical infrastructure, and $\underline{\text { limited availability of social welfare resources make caregiving more of a challenge in less }}$ developed circumstances. This reality is particularly important because of the association between HIV/AIDS and development. In less developed countries, HIV/AIDS has hit particularly hard and together with poverty creates a vicious circle where HIV thrives on poverty while deepening it (Global Forum for Health Research, 2002).

Deleted: services, which

Deleted: The statistical realities of the HIV epidemic are apparent in the contrasts between Kerala and Scotland. The differences between the respondents in the two communities are quite marked, particularly in regard to education, economic resources, and medical resources. 
In many poorer countries, carers assume the burden of caring with little or no support from external sources. In contrast, in developed countries, the advancement in medical care along with the support from statutory services make caregiving less arduous; thus enabling the carers to cope better in providing support to a family member with HIV/AIDS.

\section{Conclusion}

This exploratory study indicates that carers from Scotland utilized a wider array of coping strategies than did the carers from Kerala. These included direct strategies aimed at dealing with the source of stress, as well as indirect strategies aimed at managing emotional reactions to the problem. Having a wider array of coping strategies available may confer an advantage on the carers from Scotland as they deal with the stress of caring for a family member with HIV/AIDS.

This study suggests some important issues to be explored more fully in future research. A larger study of coping strategies in caregiving for HIV/AIDS would be helpful, as would more detailed study of the role of resources and cultural differences in coping efforts. In particular, studies could examine the influence that these factors have on the ability of the carers to engage in problem-focused coping. Similar investigations could examine the ways in which the social environment of the carers influences their coping efforts. Interventions aimed at increasing resources for caregivers could also be studied.

HIV-positive persons and their families should have the right to competent, compassionate, quality health care and social services. Article 19 of the UN Declaration of Commitment on HIV/AIDS (UNAIDS, 2001) recognises this and reiterates,

Deleted: HIV/AIDS, adopted in the General Assembly Special Session on AIDS (UNAIDS, 2001) recognizes this and reiterates, 


\begin{abstract}
...care, support and treatment can contribute to effective prevention through
increased acceptance of voluntary and confidential counselling and testing, and by keeping people living with HIV/AIDS and vulnerable groups in close contact with health-care systems and facilitating their access to information, counselling and preventive supplies (p.1)
\end{abstract}

There is an ongoing need for long-term commitment and capacity building for family carers in the fight against HIV/AIDS. Understanding how they cope and what they need to do so more effectively may help to bring about the changes necessary to support this key resource in the fight against HIV/AIDS.

\title{
References
}

Annan, K. (2006) Preface, 2006 Report on Global AIDS Epidemic, UNAIDS, Geneva

Akintola, O. (2003) Health consequences of care-giving for caregivers of PLWAs in semirural South Africa. Paper presented at the Canadian Conference on International Health, October, 2003.

Armstrong S. (2000). Caring for carers: Managing stress in those who care for people with HIV and AIDS. Geneva, Switzerland: UNAIDS. Available from http://whqLibdoc.who.int/hq/2000/UNAIDS_00.08E.pdf

Bharat, S., Aggleton, P., \& Tyrer, P. (2001). India: HIV/AIDS-related discrimination, stigma and denial. Geneva: Joint United Nations Programme on AIDS (UNAIDS).

\section{Dreze, J., \& Sen, A. (1999). Economic Development and Social Opportunity. Oxford: Oxford} University Press.

| Folkman, S., Lazarus, R., Dunkel-Scheller, C., DeLongis, A., \& Gruen, R., (1986). The dynamics of a stressful encounter: Cognitive appraisal, coping and encounter outcomes. Journal of Personality and Social Psychology, 50, 992-1003.

Deleted: Bharat, S. (1996). Facing the challenge: Household and community response to HIV/AIDS in Mumbai, India. Geneva, World Health Organisation. 9

Deleted: Billings, D. W., Folkman, S. Acree, M., \& Moskowitz, J.T. (2000). Coping and physical health during caregiving: The roles of positive and negative affect. Journal of Personality and Social Psychology, 79, 131.9

Borden, W. (1991). Stress, coping, and adaptation in spouses of older adults with chronic dementia. Social Work Research and Abstracts, 27, 14-21.9

Brown, M. (1993). Caregiving stress in families of persons with HIV/AIDS. In S. Meister, J. Bell, \& C. Gilless (Eds.), The nursing of families (pp. 211-223). Thousand Oaks CA: Sage Publications.

Deleted: Folkman, S. (1997). Positive psychological states and coping with severe stress. Social Science Medicine, $45,1207-1221$.
ब 
Global Forum for Health Research. (2002). The 10/90 Report on Health Research: 20012002. Geneva, Switzerland: World Health Organisation.

1

Hong, K., Ngyuen, T. \& Ogden, J. (2004) Understanding HIV and /AIDS-Related Stigma in Vietnam. International Center for Research on Women Research Report. ICRW, Washington. (1988). AIDS and significant others: Findings from a preliminary exploration of needs. Health and Social Work, 23, 259-265. ๆ

Human Rights Watch. (2004). Future forsaken: Abuses against children affected by HIV/AIDS in India. New York: Author.

Juma, M, Ókeyo, T., \& Kidenda, G.(2004) "Our hearts are willing, But..." Challenges of elderly caregivers in rural Kenya," Horizons Research Update. Nairobi: Population Council.

|

Knodel, J. E., Zimmer, Z. S., Kim, K. S., \& Puch, S. (2006). The impact of AIDS on olderage parents in Cambodia. Population Studies Center Research Report No. 06-594. Ann Arbor, MI: University of Michigan.

$\mid$

McGough, K. (1990). Assessing social support of people with AIDS. Oncology Nursing Forum, 17, 31-35.

McKibben, B. (2005). What is true development? The Kerala model. Retrieved March 29, 2005, from http://www.ashanet.org/library/articles/kerala.199803.html

Newton, J. (2001). AIDS stigma clouds glow of literacy: A Report from Badakara village, Kerala. London: Panos Institute.

Ogden, J., Simel, E., \& Caren, G. (2004). Expanding the care continuum for HIV/AIDS: Bringing carers into focus (Horizons Report). Washington, DC: Population Council and International Center for Research on Women.

O’Neill, J., \& McKinney, M. (2003). Care for the caregiver. In J. O’Neill, P. Selwyn, \& H. Schietinger (Eds.) HIV/AIDS Bureau, Health Resources and Services Administration. Washington, DC: US Department of Health and Human Services.

$\mid$

Deleted: Pakenham, K. L., \& Dadds, M. R. (1995). Carers' burden and adjustment to HIV. AIDS Care, 7, 189203. ๆ

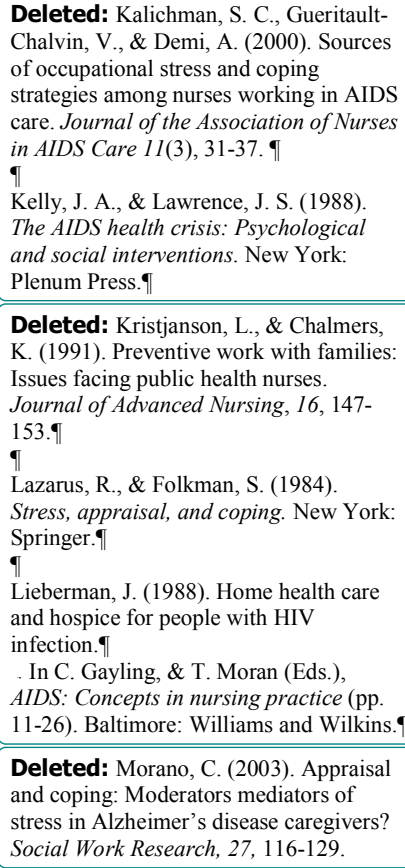

Chalvin, V., \& Demi, A. (2000). Sources of occupational stress and coping care. Journal of the Association of Nurse in AIDS Care 11(3), 31-37.

Kelly, J. A., \& Lawrence, J. S. (1988). The AIDS health crisis: Psychological Plenum Press. Issues facing public health nurses.

Jour

Lazarus, R., \& Folkman, S. (1984). Springer. infection.

. In C. Gayling, \& T. Moran (Eds.), 1-26). Baltimore: Williams and Wilkins. and coping: Moderators mediators of Social Work Research, 27, 116-129. 
Patterson, J. M. (1988). Chronic illness in children and the impact on families. In C S. Chilman, F. M. Cox, \& E. W. Nunnally (Eds.). Chronic illness and disability. Thousand Oaks, CA: Sage Publications.

Piot, P. (2006) How to reduce the stigma of AIDS: Keynote address Symposium at the XVI International AIDS Conference Toronto, 12 August 2006.

Reidy, M. (1997). Caregiving and the natural caregiver of person infected with HIV. In J. Catlan, L. Sherr, \& B. Hedge (Eds.), The impact of AIDS: Psychological and social aspects of HIV infection. Amsterdam: Harwood Academic Publishers.

Deleted: ๆ

Deleted: 9

Deleted: Pearlin, L. I., Aneshensel, C. S., \& LeBlanc, A. J. (1997). The forms and mechanisms of stress proliferation:

The case of AIDS caregivers. Journal of Health and Social Behavior, 38, 223-236.

Deleted: ๆ

Schwarzer, R., \& Schwarzer, C. (1996). A critical survey of coping instruments. In M. Zeidner \& N. S. Endler, (Eds.), Handbook of coping. New York: Wiley.

Thoits, P. A. (1986). Social support as coping assistance. Journal of Consulting and Clinical Psychology, 54, 416-423.

UNAIDS. (2001). Declaration of commitment on HIV/AIDS: Report of the United Nations General Assembly special session on HIV/AIDS. Geneva: Joint United Nations Programme on HIV/AIDS (UNAIDS).

UNAIDS. (2004). Report on the global HIV/AIDS epidemic, 2004. Geneva: Joint United Nations Programme on HIV/AIDS (UNAIDS).

UNAIDS (2006) Report on the global HIV/AIDS epidemic, 2006. Geneva: Joint United Nations Programme on HIV/AIDS (UNAIDS).

Deleted: Wolfensohn, J. (2002) Foreword. In International Bank for Reconstruction and Development, Education and HIV/AIDS: A Window of Hope: Executive Summary. Washington, DC: The World Bank.

Deleted: $\mid$

I 
The results are presented in Table 1.

\section{Table 1}

Table 1

Median Scores for Coping Scales in Kerala $(n=23)$ and Scotland $(n=5)$
Scale
Kerala
Scotland

Seeking Social Support

5

7

Positive Reappraisal

5

9

Problem Focused Coping

3

6

Self Blame

1

0 